4

5

\title{
SHEAR BEHAVIOUR OF LIGHTWEIGHT CONCRETE BEAMS
} STRENGTHENED WITH CFRP COMPOSITE

\author{
Mustafa Hameed Al-Allaf ${ }^{1}$, Laurence Weekes ${ }^{2}$ and Levingshan Augusthus-Nelson ${ }^{2}$ \\ ${ }^{1}$ University of Al-Nahrain, Baghdad, Iraq \\ ${ }^{2}$ School of Computing Science and Engineering, University of Salford, M5 4WT, United Kingdom
}

\section{ABSTRACT}

This paper presents the experimental results obtained from lightweight and normal concrete beams with closed and U-shaped configurations of epoxy bonded Carbon FRP (CFRP) reinforcement in order to compare the shear resisting mechanisms between lightweight and normal concrete beams. The experimental results show that the CFRP can successfully be applied in the strengthening of lightweight concrete beams and the shear strength gained due to CFRP reinforcement for lightweight samples is less than the normal weight concrete samples while the mode of failures are the same. In contrast, diagonal shear cracks propagate through the lightweight aggregate compared to cracks around normal aggregate in the concrete matrix. Furthermore, the numerical study shows that the design guidelines to estimate the CFRP contribution, which do not differentiate the concrete types, overestimate the U-shaped CFRP contribution on lightweight concrete beams where the effective bond length of CFRP could not be achieved due to lower tensile strength of lightweight concrete.

Keywords: Buildings, structures \& design; Composite structures; Concrete structures.

\section{List of Notations}

$\begin{array}{ll}A_{f} & \text { Area of CFRP strap } \\ E_{f} & \text { Modulus of elasticity of CFRP strap } \\ \epsilon_{f} & \text { Strain on CFRP strap } \\ V_{f} & \text { Shear resistance by CFRP straps } \\ V_{t} & \text { Total shear capacity } \\ V_{c} & \text { Shear resistance by concrete }\end{array}$


Lightweight aggregates, Pulverised Fuel Ash (Lytag, 2011), instead of coarse granite aggregates have been used in concrete structural elements. The dead weight of concrete elements are significantly reduced due to lightweight aggregate and the geometric shape of an element cast with lightweight concrete can be increased without increasing its weight. In the coming decades, it is, therefore expected that structures constructed using lightweight concrete will occupy a significant proportion of concrete infrastructures.

Lightweight concrete structures are worse affected by deterioration than normal weight structures. This is due to permanent deterioration of concrete materials, applied load more than envisaged design load and lack of understanding in behaviour of lightweight concrete as a structural material. The deteriorated lightweight concrete structures may be retrofitted to reduce the economic impact rather than replace with new structures. Thus, recent studies as recommended in ACI 440.2R (2008) have been directed to investigate efficient strengthening systems such as near surface mounted and epoxy bonded steel or FRP reinforcements in lightweight concrete structures.

Shear failure in normal concrete is a controversial topic among structural engineers (Kim and Sebastian, 2002; Sundaraja and Rajamohan, 2009; Zhang, 1997; You et al., 2017). This disparity is because the different design guidelines suggest various relative contribution of shear carrying mechanisms such as aggregate interlock, friction between the shear cracks, dowel action by longitudinal reinforcement, and contribution to the compression zone and vertical resistance by shear links. Hence, there is no single universal design method accepted in different parts of the world. When it comes to retrofitted systems with FRP, variability in materials and bond properties add to the complication in design guidelines. This problem is further amplified due to the lack of aggregate interlock and weaker tensile strength in 
lightweight concrete. In order to simplify the design guidelines for lightweight concrete, the shear capacity is treated in a similar manner to normal concrete with reduction factors both with and without a retrofitted system.

Externally bonded fibre reinforced polymer (FRP) plates or sheets have proved to be a better retrofitting system for reinforced concrete (RC) structures compared to traditional strengthening techniques. FRP has good corrosion resistance, is lightweight and has excellent mechanical properties. Furthermore, the manual strengthening system allows using the FRP reinforcements to any member's shape. A significant amount of research has been conducted to investigate the shear behaviour of normal weight concrete beams strengthened with FRP composites, including the influence of the strengthening configurations and the bonded length of the FRP reinforcement (Triantafillou, 1998; Adhikary et al., 2004), shear span to depth ratio (Khalifa and Nanni, 2002; Lee et al., 2011), size effect (Leung et al., 2007; Foster et al., 2016), shear reinforcement ratio (Pellegrino and Modena, 2002), the orientation and the width of the FRP reinforcement (Monti and Liotta, 2007; Sundaraja and Rajamohan, 2009; Mofidi and Chaallal, 2011), and type of loading (Anil, 2006 and 2008; Carolin and Täljsten, 2005). However, the study of the response of lightweight concrete (LWC) beams strengthened in shear with reinforcement has not received much attention. Hence, ACI 440.2R (2008) suggests further investigation of the effect of FRP on lightweight concrete.

In order to understand the local bond behaviour between the FRP reinforcement and lightweight concrete, experimental investigation of double-lap shear specimens were conducted by Al-Allaf et al. (2016). The test results showed that the LWC concrete has a lower bond strength compared to NWC. It is envisaged that the strengthening of LWC members will be the significant challenge for structural engineers in the coming decades. In this paper, therefore, epoxy bonded CFRP strengthening techniques in LWC beams are 
studied along with NWC in order to verify the shear reduction factors suggested by existing design guidelines and numerical models, which were developed for NWC.

\section{EXPERIMENTAL INVESTIGATION}

This study focusses on the behaviour of LWC beams externally strengthened in shear using carbon fibre reinforced polymers (CFRP) strips. Identical LWC and NWC beams were prepared and tested under monotonic loading conditions in order to compare the strengthening techniques and shear resisting mechanisms between LWC and NWC beams.

\section{SPECIMEN DESIGN}

The entire experimental program comprised six specimens cast with lightweight and normal weight concretes. Both the NWC and LWC beams were geometrically similar and cast using the same grade of concrete (i.e. the same compressive strength). The details of each series are as follows:

- Series (BL-UST/CST) comprised three beams cast with LWC without shear reinforcement except two shear links adjacent to the supports; one of the beams was without external CFRP reinforcement and the remaining two beams were each strengthened with U-shaped (UST) and close (CST) epoxy bonded external CFRP strips.

- Series (BN-UST/CST) comprised three companion beams cast with NWC without shear reinforcement except two shear links adjacent to supports either side; one beam was used as a control beam without CFRP reinforcement and two beams were strengthened with CFRP similar to the LWC beams.

All the reinforced LWC and NWC beams were designed to have the same dimensions of 200 mm wide by $300 \mathrm{~mm}$ deep and $2000 \mathrm{~mm}$ long as shown in Figure 1 . The simply supported beams were loaded under four-point loading conditions with supports located at a distance of 
$150 \mathrm{~mm}$ from the both ends of the beam. Displacement controlled monotonic loading conditions were employed. The shear span to effective depth ratio was taken as $a / d=2.27$ to secure shear failure which satisfies the definition of a shear beam (Kani, 1966). All the beams were reinforced for flexure with three bottom and two top $16 \mathrm{~mm}$ diameter longitudinal deformed steel reinforcing bars (H16 steel bar). The longitudinal steel ratio for both top and bottom reinforcement for all beams was $1.67 \%$. The flexural steel reinforcement was detailed to ensure shear failure of the samples strengthened with CFRP. The effective depth of the beam and the clear cover distance were $264 \mathrm{~mm}$ and $28 \mathrm{~mm}$ respectively.

\section{CONFIGURATION OF CFRP REINFORCEMENT}

CFRP reinforcement was used in this test with various shear strengthening systems as illustrated in Table 1. Closed-shaped CFRP reinforcements were attached as strips on all the faces of the beam. Also, U-shaped systems were attached on the tension (bottom) and the two side faces of the beam as strips. The CFRP reinforcements were orientated at $90^{0}$ with respect to the longitudinal axis of the beam as shown in Figure 2. The width of CFRP reinforcement was $100 \mathrm{~mm}$ and the spacing of $150 \mathrm{~mm}$ from centre-to-centre of the attached CFRP strips. These CFRP reinforcements were attached along the shear span of the beam, from the support point up to the point of load application on both sides of the beam.

Table1: Summary of test parameters

\begin{tabular}{|c|c|c|c|c|}
\hline Sample & $\begin{array}{c}\text { CFRP ratio } \\
(\%)\end{array}$ & $\begin{array}{c}\text { CFRP } \\
\text { strengthening type }\end{array}$ & $\begin{array}{c}\text { CFRP } \\
\text { orientation }\end{array}$ & $\begin{array}{c}\text { CFRP warp } \\
\text { coverage }\end{array}$ \\
\hline BL & 0 & - & - & - \\
\hline BL- UST & 0.0785 & U-shaped & $90^{0}$ & Strip \\
\hline BL- CST & 0.0785 & Closed-shaped & $90^{0}$ & Strip \\
\hline BN & 0 & - & - & - \\
\hline BN- UST & 0.0785 & U-shaped & $90^{0}$ & Strip \\
\hline BN- CST & 0.0785 & Closed-shaped & $90^{0}$ & Strip \\
\hline
\end{tabular}




\section{MATERIAL PROPERTIES}

115 Pulverised Fuel Ash (Lytag) instead of course aggregates were used in the preparation of the

116 lightweight concrete mixture. The particle size grading, physical properties and chemical

117 composition of the Lytag aggregates are reported by Al-Allaf et al. (2016). The concrete

118 mixes for both concrete types were designed to have a slump of $75 \mathrm{~mm}$, and a 28-day cube

119 compressive strength of $40 \mathrm{~N} / \mathrm{mm}^{2}$. The mix details for the lightweight and normal weight

120 concretes are given in Table 2. All the LWC and NWC samples were cast in a single batch

121 each. Furthermore, a total of 18 concrete cubes $(100 \times 100 \times 100 \mathrm{~mm})$, eight concrete

cylinders (150 dia. x $300 \mathrm{~mm})$ and six prisms $(100 \times 100$ x $400 \mathrm{~mm})$ were cast from each

batch to determine the uniaxial compressive strength, the Young's modulus of elasticity, the

concrete density and the modulus of rupture of lightweight and normal weight concretes (see

Table 2: The mix design of lightweight and normal weight concretes

\begin{tabular}{|c|l|l|l|c|c|}
\hline Concrete type & $\begin{array}{l}\text { Water } \\
(\mathrm{kg})\end{array}$ & $\begin{array}{l}\text { Cement } \\
(\mathrm{kg})\end{array}$ & $\begin{array}{l}\text { Sand } \\
(\mathrm{kg})\end{array}$ & $\begin{array}{c}\text { Coarse } \\
\text { aggregate } \\
(\mathrm{kg})\end{array}$ & $\begin{array}{c}\text { Design } \\
\text { strength } \\
\left(\mathrm{N} / \mathrm{mm}^{2}\right)\end{array}$ \\
\hline NWC & 192 & 400 & 667 & 1184 & 40 \\
\hline LWC & $216^{*}$ & 480 & 485 & 715 & 40 \\
\hline
\end{tabular}

* The moisture content and absorption of lightweight aggregates were considered in calculations of mix design.

Table 3: Mechanical properties of concretes

\begin{tabular}{|c|c|c|c|c|}
\hline $\begin{array}{l}\text { Concrete } \\
\text { type }\end{array}$ & $\begin{array}{c}\text { Average concrete } \\
\text { compressive } \\
\text { strength } \\
(\mathrm{MPa})\end{array}$ & $\begin{array}{c}\text { Average } \\
\text { modulus of } \\
\text { rupture } \\
(\mathrm{MPa})\end{array}$ & $\begin{array}{c}\text { Average } \\
\text { modulus of } \\
\text { elasticity } \\
(\mathrm{MPa})\end{array}$ & $\begin{array}{c}\text { Average } \\
\text { concrete density } \\
\left(\mathrm{kg} / \mathrm{m}^{3}\right)\end{array}$ \\
\hline NWC & 42.1 & 3.49 & 29860 & 2356 \\
\hline LWC & 43.34 & 3.026 & 23510 & 1823 \\
\hline
\end{tabular}


For steel reinforcing bars, three samples of longitudinal bars were tested in uniaxial tension.

131 Average properties of steel reinforcement are listed in Table 4.

Table 4: Mechanical properties of $16 \mathrm{~mm}$ diameter steel bar

\begin{tabular}{|c|c|c|c|c|}
\hline $\begin{array}{c}\text { Yield stress } \\
(\mathrm{MPa})\end{array}$ & $\begin{array}{c}\text { Yield strain } \\
(\mu \mathrm{m} / \mathrm{m})\end{array}$ & $\begin{array}{c}\text { Ultimate stress } \\
(\mathrm{MPa})\end{array}$ & $\begin{array}{c}\text { Ultimate strain } \\
(\mathrm{mm} / \mathrm{m})\end{array}$ & $\begin{array}{c}\text { Modulus of } \\
\text { elasticity } \\
(\mathrm{GPa})\end{array}$ \\
\hline 510 & 2600 & 650 & 130000 & 200 \\
\hline
\end{tabular}

133

Mechanical properties of the unidirectional CFRP sheets (C Sheet 240) and primer resin are summarised in Table 5 (Weber UK, 2008). Epoxy plus primer (EN-Force primer) and epoxy plus adhesive (EN-Force bonding adhesive) were used to bond the CFRP composite to the surface of the concrete. Two-thirds of the adhesive as the base component and one-third of hardener were used according to the manufacturer's recommendations.

\begin{tabular}{|c|c|}
\hline \multicolumn{2}{|c|}{ CFRP sheet } \\
\hline Modulus of elasticity & $240 \mathrm{GPa}$ \\
\hline Tensile strength & $4000 \mathrm{MPa}$ \\
\hline Strain at failure & $1.6 \%$ \\
\hline \multicolumn{2}{|c|}{ Primer resin } \\
\hline Compressive strength & $100 \mathrm{~N} / \mathrm{mm}^{2}$ \\
\hline Tensile strength & $19 \mathrm{~N} / \mathrm{mm}^{2}$ \\
\hline Flexural strength & $30 \mathrm{~N} / \mathrm{mm}^{2}$ \\
\hline Bond to concrete & $>5.3 \mathrm{~N} / \mathrm{mm}^{2}$ \\
\hline Modulus of elasticity & $5 \mathrm{kN} / \mathrm{mm}^{2}$ \\
\hline
\end{tabular}

A concrete grinder machine was used to smooth the surface of the concrete in order to achieve the required level of stress transference between the CFRP and the surface of the concrete. Then, the surface was cleaned to remove the dust produced during the grinding process. Samples corners were rounded to prevent unwanted CFRP rupture which can be developed as a result of the high-stress concentration in the CFRP reinforcement wrapped 
147 close the corner of the beam. For the U-shaped systems, the CFRP reinforcement was 148 attached directly below the top surface of the beams by approximately $20 \mathrm{~mm}$.

\section{TEST ARRANGEMENT}

151

152

The four-point loading arrangement shown in Figure 3 was used. A $500 \mathrm{kN}$ load cell attached to a hydraulic jack was used to record the applied load during the test, with monotonic loads applied via a spreader beam. This spreader beam was seated on $25 \mathrm{~mm}$ diameter steel rollers welded to steel plates (length=200 $\mathrm{mm}$ and width=100 $\mathrm{mm}$ ) bedded on the top surface of the sample to avoid local crushing of concrete at the load point. The sample is placed over the two support points with a $25 \mathrm{~mm}$ diameter steel roller seated on the top surface of a $100 \mathrm{~mm}$ steel plate. One of the steel rollers was welded to the steel plate, and a (length=200 $\mathrm{mm}$ and width=100 mm) steel plate was provided on top of the roller to avoid local crushing of concrete at the support as shown in Figure 3.

\section{INSTRUMENTATION}

\section{Steel Strain Gauges}

Ten FLA-6-11 uni-directional strain gauges by Tokyo Sokki Company were used to record the strain measurements at different positions along the length of the middle bar in the bottom layer in each of the normal and lightweight samples. The gauge factor, gauge resistance and the gauge length were $2.12 \pm 1 \%, 120 \pm 0.5 \Omega$ and $6 \mathrm{~mm}$ respectively. Strain gauges were positioned externally at $250 \mathrm{~mm}, 400 \mathrm{~mm}, 550 \mathrm{~mm}, 700 \mathrm{~mm}$, and $850 \mathrm{~mm}$ from both ends of each beam, as shown in Figure 4. The gauges were denoted as "LS" combined with a number starting from 1 to 10 to identify their location from the left end of the beam. 


\section{CFRP Strain Gauges}

170

171

172

173

174

Figure 5 illustrates the strain gauges employed in the CFRP reinforcement during the test. The strain gauges and CFRP strip were denoted as "SG" and "SF" respectively. The type FLA-5-11 strain gauge by Tokyo Sokki Company measures a uni-directional strain, which was orientated vertically and has a gauge factor and length of $2.12 \%$ and $5 \mathrm{~mm}$ respectively. The same arrangements were employed for all LWC and NWC strengthened samples.

\section{Linear Variable Differential Transformers (LVDTs)}

Three Linear Voltage Displacement Transducers (LVDTs) were used in this test to record vertical deflections at various positions along the sample as shown in Figure 6. The LVDTs were mounted on a frame connected to the centre of concrete directly above the supports to measure the relative displacement along the beams.

\section{EXPERIMENTAL RESULTS}

A summary of the samples shear strength based on the maximum shear carrying capacity, the recorded mid-span deflection and the modes of failure are summarised in Table 8.

Table 8: Summary of the shear capacities, failure deflection and modes of failure

\begin{tabular}{|c|c|c|c|}
\hline Sample & $\begin{array}{c}\text { Max Shear } \\
\text { capacity }(\mathrm{kN})\end{array}$ & $\begin{array}{c}\text { Mid-span } \\
\text { Deflection at failure (mm) }\end{array}$ & $\begin{array}{l}\text { Failure mode, } \\
\text { CFRP failure }\end{array}$ \\
\hline BL & 151.78 & 4.82 & Failure in shear \\
\hline BL-UST & 218.38 & 7.10 & $\begin{array}{l}\text { Failure in shear due to } \\
\text { CFRP debonding }\end{array}$ \\
\hline BL-CST & 267.14 & 11.3 & $\begin{array}{l}\text { Failure in shear due to } \\
\text { CFRP rupture }\end{array}$ \\
\hline $\mathrm{BN}$ & 164.1 & 5.35 & Failure in shear \\
\hline BN-UST & 248.6 & 7.69 & $\begin{array}{l}\text { Failure in shear due to } \\
\text { CFRP debonding }\end{array}$ \\
\hline BN-CST & 320.8 & 10.3 & $\begin{array}{l}\text { Failure in shear due to } \\
\text { CFRP rupture }\end{array}$ \\
\hline
\end{tabular}

Comparison of the maximum shear failure loads between CFRP-retrofitted samples and the reference sample reveals that the CFRP retrofitting systems were efficient in improving the 
shear strength of the LWC and NWC beams. Figure 7(a) shows the shear strength gained due to CFRP reinforcement in the strengthened samples compared with the corresponding control samples of LWC and NWC. For the LWC series, the shear strength provided by CFRP reinforcement for U-shaped and Closed-shaped samples were $44 \%$ and $76 \%$ respectively, when compared with the control sample, while for the NWC series, the shear strength provided by CFRP reinforcement for U-shaped and Closed-shaped samples were 51\% and 95\% respectively.

In this study, the shear strength of the control, U- shaped and Closed-shaped samples of LWC are $92 \%, 87 \%$ and $83 \%$ of the control, U-shaped and Closed-shaped samples of the corresponding NWC samples respectively.

All the strengthened samples demonstrate increases in the maximum deflection over the control samples at failure as shown in Figure 7(b) and Table 8. LWC and NWC samples strengthened with U- shaped CFRP had $47 \%$ and $43 \%$ greater maximum deflection at failure over the control LWC and NWC samples. Comparison with samples strengthened with Closed-shaped CFRP had an increase in maximum deflection at failure of 134\% and 93\% respectively. This observation resulted from the evidence that crack bridging forces provided by CFRP reinforcements could increase the shear strength of LWC and NWC beams and yielded a better ductility over the control samples. In contrast, LWC samples demonstrated lower shear enhancement while producing higher ductile behaviour compared to corresponding NWC samples. Increases in interfacial and shear stresses with increasing plastic deformation leads to CFRP debonding and unexpected CFRP rupture failures, thus the effectiveness of FRP for shear strengthening LWC beams will be affected by this issue. This observation can be attributed to a lower concrete surface tensile strength, aggregate interlock at the diagonal crack faces and requirement for longer effective bond length in LWC as observed by Al-Allaf et al. (2016 and 2015). CFRP bond deterioration in LWC requires 
consideration to ensure the safety of CFRP applications for shear strengthening of LWC beams.

\section{LOAD-DEFLECTION RESPONSE}

215

The shear-deflection response curves for all the specimens are compared in Figure 8. The behaviour trends for NWC and LWC samples are described by three zones of stiffness's: (i) elastic stiffness zone (elastic behaviour), (ii) flexural stiffness zone, and (iii) shear stiffness zone. In general, all LWC and NWC beams showed the same elastic stiffness zone before first flexural cracks (approximately $50 \mathrm{kN}$ ). The flexural stiffness zone showed the same linear trend until a diagonal crack appeared at the surface of concrete at the applied load between 100-130 kN load range for NWC beams and 90-120 kN load range for LWC beams. As illustrated in Figure 8, the lightweight control sample (BL) reached a maximum load of $151.78 \mathrm{kN}$ and corresponding mid-span deflection of $4.30 \mathrm{~mm}$. An abrupt increase in applied load developed at this stage as a result of the diagonal shear crack opening width. The strengthened LWC samples (BL-UST and BL-CST) exhibit identical stiffness at low level loading. This can be attributed to the configuration of the CFRP which would not influence the stiffness until the diagonal shear crack developed. However, at the maximum load for Closed-shaped samples, the shear cracking zone was considerably higher than those observed in the samples with the U-shaped system. This is assigned to the premature failure for samples strengthened with the U-shaped system where effective length of CFRP bond was not available. It can be noticed that the NWC samples displayed similar shear deflection shapes to the corresponding LWC samples.

Figure 8 also shows that the stiffness of LWC samples is lower than those of NWC samples with identical CFRP strengthening configurations after initial cracking. This behaviour is a result of the variance in rigidities of the LWC tested samples. LWC samples had lower 
stiffness compared with NWC samples due to lower stiffness of lightweight aggregate

237 (LWA) particles and higher cement ratio (Clarke, 2002).

Both controlled and U-shaped LWC and NWC samples (BL, BN, BL-UST and BN-UST)

failed immediately after reaching the maximum load carrying capacity. This is due to the fact that the crack bridging force across the diagonal crack was not available or fully reached its capacity in the controlled and U-shaped retrofitted systems respectively. However, both closed-shaped LWC and NWC samples (BL-CST and BN-CST) exhibited a plastic behaviour before the rupture of CFRP sheets.

\section{FAILURE MODES}

All the tested LWC and NWC beams failed in shear by initiation of diagonal tension cracks in the shear span. Loss of friction at the crack interfaces and shear rotation were the failure modes of the control samples. In the case of samples retrofitted with CFRP reinforcements, the CFRP strips either debonded or ruptured as shown in Figure 9. The inclinations of diagonal tension shear cracks are summarised in Table 9, which are numbered from 1 to 3 according to their location from the left end of the beam. In general, the orientation of the diagonal tension crack for strengthened samples was lower than their corresponding control samples. Furthermore, there is no variance in response between corresponding lightweight and normal weight samples regarding the inclinations of diagonal shear cracks despite the clear difference in ultimate shear loads.

Table 9: Inclination of diagonal shear cracks

\begin{tabular}{|c|c|c|c|c|}
\hline \multirow{2}{*}{ Sample } & \multicolumn{3}{|c|}{ Inclination of diagonal shear cracks } & \multirow{2}{*}{ Average inclination } \\
\cline { 2 - 3 } & $\theta_{1}$ & $\theta_{2}$ & $\theta_{3}$ & \\
\hline BL & $42^{0}$ & $40^{0}$ & & $41^{0}$ \\
\hline BL-UST & $34^{0}$ & $30^{0}$ & & $32^{0}$ \\
\hline BL-CST & $33^{0}$ & $37^{0}$ & $35^{0}$ & $35^{0}$ \\
\hline BN & $41^{0}$ & $44^{0}$ & & $42^{0}$ \\
\hline BN-UST & $33^{0}$ & & & $33^{0}$ \\
\hline BN-CST & $35^{0}$ & $37^{0}$ & $34^{0}$ & $35^{0}$ \\
\hline
\end{tabular}


257 The CFRP reinforcements have significant effects on the beams crack distributions. The CFRP reinforcements delay the loss of friction by reducing the diagonal crack opening width. This was achieved by the confinement and crack bridging effects of CFRP. At the ultimate limit state, the crack bridging effect was lost and the loss of friction occurred suddenly without any warning. The failure patterns are extremely brittle when compared to the control samples. The same failure modes were observed by Bousselham \& Chaallal (2008).

Shear failure as a result of CFRP debonding was the failure mode of the LWC sample strengthened with U-shaped CFRP (BL-UST). The failure in bond between CFRP and concrete was initiated by debonding in a thick layer of lightweight concrete close the surface of the beam, (see Figure 9(c)). The CFRP reinforcement was detached locally from the surface of concrete at the diagonal shear cracks. With more loading, the debonding failure gradually extended from the crack and moved away towards the top and the bottom of the beam. A similar failure mode was observed for the NWC sample strengthened with U-shaped CFRP (BN-UST) except the CFRP debonding initiated with a thin layer of normal concrete (close to the concrete surface)(see Figure 9(d)). Generally, BL-UST showed higher crack intensity and widths compared with BN-UST. The average major diagonal crack widths in BL-UST and BN-UST were about 7 and 4 mm respectively.

In contrast, LWC and NWC samples strengthened with Closed-shaped CFRP (BL-CST and BN-CST) failed due to CFRP rupture (see Figure 9(e) and (f)). CFRP fibres across the diagonal shear crack snapped one-by-one because of excessive straining. These samples also failed in extremely brittle manner compared with the control samples. Furthermore, CFRP rupture caused larger increases in shear strength compared to CFRP debonding failure. This can be attributed to longer effective bond length in the Closed-shaped CFRP. Each of the 
samples had few diagonal shear cracks. However, no significant difference in the crack pattern was observed between lightweight and normal weight samples. Furthermore, the failures of the samples were due to a single diagonal crack. The average major diagonal crack widths in BL-CST and BN-CST were about 4 and 3 mm respectively.

It was noticed that the LWC samples exhibited low shear strengths and weaker friction between crack faces. In this study, microstructural examinations using a light microscope and a scanning electron microscope (SEM) were conducted on a sample of lightweight and normal weight concrete collected from the crack faces in order to examine the macro/micro and nano internal pore structures. These methods were implemented to support the behaviour observed in the disruptive failure test. Interestingly, light micrographs of lightweight concrete samples show that the path of diagonal tension cracks propagated through the lightweight aggregates (see Figure 10 (a)) rather than in the concrete matrix around the aggregates as in normal weight samples (see Figure 11 (a)). This could be attributed to the lower tensile strength of lightweight aggregate compare to normal weight aggregate. Hence, it can be concluded that the energy required for the crack opening through the lightweight aggregates is less than the crack propagation around the coarse aggregates. Due to the cracks though the aggregates, the crack faces do not have a significant amount to surface interlock, which is common in normal weight concrete. Therefore, the aggregate interlock between the crack faces could be neglected in lightweight concrete beams and this eventually leads to the lower shear capacity of lightweight concrete beams.

The SEM micrographs of the lightweight concrete sample revealed the spherical shapes of Lytag particles with an extremely porous microstructure (see Figure 10 (b) to (e)). In contrast, the normal weight aggregates are angular in shape with a non-porous surface (see Figure 11 (c)). Furthermore, the lightweight aggregate is surrounded by an orange coloured area (reacted zone) (see Figure 10 (a)). This is due to the chemical reaction between the 
lightweight particles and the cement matrix. Figure 10 (c) shows the reacted zone and the microstructure of lightweight particles, in which the voids are considerably higher than the cement paste. Also, Figure 10 (d) illustrates the boundary between the reacted zone and the cement paste. It can also be observed that the cement paste and lightweight particles are well interlocked as illustrated in the typical microstructure of the interfacial zone for a composite of Lytag particle and cement paste (see Figure 10 (a)).

Figures 11(b) and (d) show that the normal aggregates are bonded with the cement paste rigidly and cracks develop around the aggregates. In this case the aggregate interlock between the crack faces potentially provides significant contribution to the ultimate shear carrying capacity.

\section{LONGITUDINAL STEEL STRAIN}

The longitudinal steel reinforcement was slightly strained at the earlier stage of loading and starts to elongate with the occurrence of flexural or shear cracks. Yielding of the central steel bar was not observed in the control normal and lightweight samples due to premature shear failure. Furthermore, it was noted that the tested samples showed approximately the same elongations at a low level of loading on both sides of the LWC and NWC samples. Longitudinal steel strain profiles of samples BL-CST and BN-CST at various load levels (20\%, $40 \%, 60 \%, 80 \%$, and $100 \%$ of the maximum shear capacity) are presented in Figure 12, where the horizontal black line represents the yield strain of the steel. Variance in strain measurements was noticed at a higher level of loading in several samples, which can be attributed to the position, number and effect of diagonal shear and flexural cracks. For BLCST, the recorded strains close to the centre of the beam are lower compared with corresponding BN-CST, except at the ultimate load (100\%) as shown in Figure 12 (a) and (b). Similar behaviour was observed between the BL-UST and BN-UST samples. This behaviour can be attributed to the multiple hair-line flexural cracks observed in the middle of 
the beam and initiation of shear cracks close to the applied load for the normal weight concrete samples. In contrast, diagonal shear cracks close to support in lightweight concrete samples were prevalent. The strain distributions at the ultimate load of both LWC and NWC samples were similar. Hence, the contribution of dowel action by longitudinal reinforcement for shear resistance in LWC and NWC samples could be considered as the same at the ultimate load (Martin-Perez and Pantazopoulou, 2001).

\section{CFRP STRAIN}

The average strain response of CFRP reinforcement is characterised by two stages: the first stage is where the CFRP strains are very small and the second stage where an abrupt increase of CFRP strains develops with further loading. The first considerable increase in CFRP strains developed at an applied load of $100 \mathrm{kN}$ for BL-UST, $120 \mathrm{kN}$ for BL-CST, $110 \mathrm{kN}$ for BN-UST and $130 \mathrm{kN}$ for BN-CST. It can be noted that the LWC samples has a slightly lower applied load at the point of shear crack initiation. This observation was related to the crack propagation across the CFRP strips. This crack would subsequently initiate into the diagonal shear crack that could lead to failure of the sample. Up to this loading point (initial crack load), the contribution of the CFRP reinforcement to the total shear strength of the reinforced concrete beam is very small and can be ignored. With further loading, the crack opening increases and new shear cracks develop, leading to an increase in CFRP stress due to crack bridging forces of the CFRP strips. The sudden decrease in CFRP strains which is observed at higher level of loading in some of the instrumented CFRP strips for samples with U-shaped reinforcement. This is could be attributed to the global debonding of the CFRP reinforcement from the surface of the concrete.

The CFRP strains of all the effective straps at the failure loads are summarised in Table 10. A significant difference in measured CFRP strains between U-shaped and Closed-shaped samples were observed. This is attributed to the premature failure of samples with the U- 
shaped strengthening technique. Samples with Closed-shaped CFRP reinforcement were able

357 to sustain larger strains compared with U-shaped samples.

358 Generally, the stress distribution in the RC beam is complex and may affect the CFRP-to359 concrete interface, with an expectation to accelerate CFRP debonding and to minimise the 360 maximum debonding strain. The increase in interfacial and normal stresses with increasing 361 plastic deformation in lightweight concrete beams leads to unexpected CFRP reinforcement failures and thus a reduction in the maximum debonding strains.

Table 10: Summary of maximum local CFRP strains at sample failure

\begin{tabular}{|c|c|c|c|c|c|c|c|}
\hline Sample & $\begin{array}{c}\text { Shear force } \\
\mathbf{( k N )}\end{array}$ & \multicolumn{5}{|c|}{$\begin{array}{c}\text { Strains at failure from individual gauges at each } \\
\text { instrumented CFRP strips ( } \mathbf{\mu m} / \mathbf{m})\end{array}$} \\
\cline { 4 - 8 } & & $\mathbf{S F 1}$ & $\mathbf{S F 2}$ & $\mathbf{S F 3}$ & $\mathbf{S F 4}$ & $\mathbf{S F 5}$ & SF6 \\
\hline BL-UST & 218.4 & 4011.6 & 4725.9 & 2911.0 & $\mathbf{4 7 2 8 . 6}$ & 4216.7 & 1662.4 \\
\hline BL-CST & 267.1 & 5819.4 & $\mathbf{5 9 7 2 . 5}$ & 4800.3 & 2788.3 & 4466.5 & 1846.8 \\
\hline BN-UST & 248.6 & 2120.8 & $\mathbf{5 8 3 7 . 5}$ & 664.5 & 1642.6 & 846.1 & 4919.4 \\
\hline BN-CST & 320.8 & 2393.0 & $\mathbf{9 4 1 6 . 0}$ & 7893.2 & 2579.8 & 1948.1 & 4711.9 \\
\hline
\end{tabular}




\section{SHEAR COMPONENT ANALYSIS}

366 The shear contribution of CFRP was calculated using two different methods. Firstly the subtraction method allows the calculation of the shear contribution provided by the concrete and CFRP reinforcements using the difference in failure loads between samples, which is useful in understanding the efficiency of CFRP reinforcement. This method is derived based on the concept that the shear contribution by the additional confinement effect of concrete in the presence of CFRP at failure load could be negligible (Khalifa and Nanni, 2002). This method can be illustrated using a simple free-body diagram of half of the cracked beam as shown in Figure 13.

Secondly, the shear contribution of the CFRP strips can be evaluated by summing the contribution provided by CFRP reinforcement across the diagonal shear crack at each side of the beam, as shown in Equation 1:

$$
V_{f}=\sum_{i=1}^{n} A_{f i} E_{f} \varepsilon_{f i}
$$

where $V_{f}$ is the estimated shear force provided by the CFRP reinforcement, $A_{f}$ is the area of the CFRP strip, $E_{f}$ is the elastic modulus of CFRP material, $\varepsilon_{f}$ is the strain determined from strain gauges attached to the CFRP strip and $n$ is the number of stirrups or CFRP strips crossing the observed critical shear crack,. The relative contribution of shear resistance by various mechanisms (i.e., tensile strength of concrete, aggregate interlock at the diagonal crack faces, compressive strength of concrete, interfacial shear stress, dowel action provided by the longitudinal steel reinforcement) were not fully understood so far (Kim, 2011). Hence, the shear contributions of these mechanisms of concrete beam with longitudinal reinforcement were considered together in this study. The concrete contribution $\left(V_{c}\right)$ was 
obtained by subtracting the estimated contributions of CFRP reinforcement $\left(V_{f}\right)$ from the total shear capacity at a particular load level $\left(V_{t}\right)$ as given by Equation (2):

$$
V_{c}=V_{t}-V_{f}
$$

389

390

391

392

Figure 14 shows the results of the shear component analysis for the LWC and NWC beam specimens. In these figures, the horizontal axis represents the total applied load recorded by the load cell and the vertical axis represents the total shear contribution of concrete and CFRP reinforcements on both sides of the beam. It can be noted that the shear strength provided by CFRP reinforcement was very small and can be ignored before the occurrence of a diagonal shear crack. In this stage, external loads applied to the samples are mainly resisted by the concrete. As the diagonal shear crack develops, a part of the load is taken by the CFRP reinforcement as demonstrated by a sudden leap in the CFRP shear contribution response curves. The CFRP reinforcement gradually carries the external shear force until the CFRP reinforcement detaches from the surface of the concrete or ruptured. Abrupt falls in the CFRP shear contribution can be highlighted when the CFRP reinforcement debonds or ruptures before the sample failure (see Figure 14(c)). A similar response was observed in experimental investigations conducted by Bousselham and Chaallal (2008). It can be concluded that there was virtually no difference between the lightweight samples and their normal weight companions regarding the general trend of the CFRP reinforcement contribution, a similar response was observed for all the tested samples. However, the contribution of CFRP in LWC is slightly lower than the corresponding NWC samples.

Table 11 summarises the maximum shear contribution provided by concrete and the CFRP. Interestingly, the CFRP contribution to shear using the subtraction method of analysis is very close to the values when the strain readings are used to evaluate the shear strength component provided by CFRP reinforcement. Hence the additional confinement effect in the presence of CFRP can be neglected based on the subtraction method of analysis. 
413 Table 11: Maximum shear contribution provided by concrete and the CFRP reinforcement

\begin{tabular}{|c|c|c|c|c|}
\hline Sample & $\begin{array}{c}\text { Total shear } \\
\text { capacity }(\mathrm{kN})\end{array}$ & \multirow{2}{*}{$\begin{array}{c}\text { Subtraction } \\
\text { Method of } \\
\text { Analysis }(\mathrm{kN})\end{array}$} & \multicolumn{2}{|c|}{$\begin{array}{c}\text { Shear strength provided by } \\
\text { concrete } \\
\text { and CFRP reinforcement }\end{array}$} \\
\cline { 4 - 5 } & & & $V_{f}(\mathrm{kN})$ & $V_{c}(\mathrm{kN})$ \\
\hline BL & 151.78 & 0 & 0 & 151.78 \\
\hline BL-UST & 218.38 & 66.6 & 68.6 & 149.82 \\
\hline BL-CST & 267.14 & 115.4 & 118.6 & 148.53 \\
\hline BN & 164.1 & 0 & 0 & 164.1 \\
\hline BN-UST & 248.6 & 84.5 & 84.1 & 164.3 \\
\hline BN-CST & 320.8 & 156.7 & 159.7 & 161.1 \\
\hline
\end{tabular}

414

415 COMPARISON WITH DESIGN CODES AND GUIDELINES

416 Current design codes and guidelines such as ACI 318-08 (2008), CAN/CSA-S6 (2006) and

417 Eurocode2 (2014) present calculations for the shear carrying capacity of normal weight

418 reinforced concrete beams. In order to calculate the shear resistance of lightweight concrete,

419 a reduction factor was proposed. ACI 318-08 suggests to use 0.85 as the reduction factor.

420 Eurocode 2 provides a reduction factor which is related to density of the lightweight concrete.

421 However, the shear prediction of CAN/CSA-S6 includes the density of concrete. Therefore,

422 the density of lightweight concrete could be used for the prediction of shear strength. Shear

423 predictions of normal and lightweight concretes illustrates that the CAN/CSA-S6 are close to

424 experimental results (see Table 12). The predication of ACI 318-08 and Eurocode 2

425 underestimate the shear capacity of the control lightweight and normal weight samples. This

426 may be attributed to the arching effects developed by the low shear span-to-depth ratio

$427(\mathrm{a} / \mathrm{d}=2.2)$ which increases the shear resistances of the tested samples.

428

Table 12: Experimental and predicted results of control samples

\begin{tabular}{|c|c|c|c|c|}
\hline Sample & $\begin{array}{c}\text { Experimental result } \\
(\mathrm{kN})\end{array}$ & $\begin{array}{c}\text { ACI 318-08 } \\
(\mathrm{kN})\end{array}$ & $\begin{array}{c}\text { Eurocode } 2 \\
(\mathrm{kN})\end{array}$ & $\begin{array}{c}\text { CAN/CSA-S6 } \\
(\mathrm{kN})\end{array}$ \\
\hline $\mathrm{BN}$ & 164.1 & 116.6 & 120.3 & 164.6 \\
\hline $\mathrm{BL}$ & 151.8 & 100.5 & 100.3 & 137.9 \\
\hline
\end{tabular}


430 Furthermore, ACI 440.2R (2008), TR-55 (2013) and CAN/CSA-S6 (2006) allow the

431 estimation of the contribution of CFRP separately to the concrete contribution. The 432 experimental results (using the subtraction method of analysis, from Table 11) and numerical 433 predictions using the current design codes for the CFRP contribution of the tested LWC and $434 \quad$ NWC beams are summarised in Table 13.

Table 12: Experimental and predicted results of CFRP shear contribution for strengthened samples

437

\begin{tabular}{|c|c|c|c|c|}
\hline Sample & $\begin{array}{c}\text { CFRP contribution from } \\
\text { subtraction method } \\
(\mathrm{kN})\end{array}$ & $\begin{array}{c}\text { ACI 440.2R } \\
(\mathrm{kN})\end{array}$ & $\begin{array}{c}\text { TR-55 } \\
(\mathrm{kN})\end{array}$ & $\begin{array}{c}\text { CAN/CSA-S6 } \\
(\mathrm{kN})\end{array}$ \\
\hline BL-UST & 66.6 & 73.6 & 72.1 & 71.6 \\
\hline BL-CST & 115.4 & 79.6 & 79.6 & 79.6 \\
\hline BN-UST & 84.5 & 73.4 & 70.2 & 71.6 \\
\hline BN-CST & 156.7 & 79.6 & 79.6 & 79.6 \\
\hline
\end{tabular}

The predictions of the ACI 440.2R (2008), TR-55 (2013) and CAN/CSA-S6 (2006)

overestimate the contributions of U-shaped CFRP reinforcement of the LWC retrofitted beam

441

(BL-UST). These codes use the concrete compressive strength for the prediction of CFRP

442 contribution. As noticed, the tensile strength and the bond strength between lightweight

443 concrete and FRP are significantly low compared to normal weight concrete while 444 compressive strengths are the same. Furthermore, BL-UST has a limited bond length. 445 Therefore, the prediction of the CFRP contribution on LWC beams using design guidelines should be modified with available effective length and tensile strength of concrete. 
This study investigated the efficiency of epoxy-bonded CFRP strips on lightweight concrete in shear. While the normal weight concrete samples agrees with the existing experimental and numerical studies, the following conclusion can be derived on lightweight concrete samples:

- The shear strength gained due to CFRP reinforcement for lightweight samples is less than the normal weight concrete samples. This is probably attributed to lower concrete surface tensile strength and aggregates interlock.

- The test observations reveal that there was virtually no difference between the lightweight beams and their normal weight companions regarding the failure modes and shear cracks inclinations. However, it was noticed that the path of diagonal tension cracks on the tested LWC samples propagated through coarse aggregates rather than in the concrete matrix around the aggregates as in normal weight samples. It can be also concluded that the LWC samples had higher cracks width due to lower aggregate interlock at the primary shear crack interface.

- Samples with Closed-shaped CFRP reinforcement experienced higher CFRP strains compared with U-shaped sample, which failed due to the premature debonding of the CFRP reinforcement from the surface of concrete. Furthermore, numerical predictions using design guidelines and codes overestimate the CFRP contribution in the lightweight concrete beam strengthened with U-shaped CFRP system. This is result of insufficient bond length, which significantly influenced by the tensile strength of lightweight concrete (Al-Allaf et al., 2016).

- Therefore, the effect of CFRP on lightweight concrete should receive more attention in the current design codes and guidelines, which were derived and verified using experimental results of FRP strengthened system on normal weight concrete. Further 

analytical and experimental studies are required to include the characteristics of the FRP/ lightweight joints in current codes and guidelines to evaluate the efficiency of using FRP reinforcement to strength LWC structures where the effective bond could not be achieved.

\section{ACKNOWLEDGMENTS}

476 Our thanks to "University of Al-Nahrain and Iraqi Ministry of Higher Education and 477 Scientific Research (MOHESR)’’ for funding this research.

\section{REFERENCES}

479 - ACI 318-08, 2008. Building code requirements for structural concrete and commentary. 480 ACI Committee 213, American Concrete Institute. Farmington Hills, Michigan.

- ACI 440.2R-08, 2008. Guide for the design and construction of externally bonded FRP 482 systems for strengthening concrete structures. ACI Committee 440, American Concrete $483 \quad$ Institute. Farmington Hills, Michigan.

- Adhikary, B.B., Mutsuyoshi, H. and Ashraf, M., 2004. Shear strengthening of reinforced concrete beams using fiber-reinforced polymer sheets with bonded anchorage. Structural Journal, 101(5), pp.660-668.

- Al-Allaf, M.H., Weekes and L., Augusthus-Nelson, 2015. Experimental study on bondslip behaviour between CFRP sheets and lightweight concrete. In proceedings of the $8^{\text {th }}$ Biennial Conference on Advanced Composites in Construction (ACIC 2015).

- Al-Allaf, M.H., Weekes, L., Augusthus-Nelson, L. and Leach, P., 2016. An experimental investigation into the bond-slip behaviour between CFRP composite and lightweight concrete. Construction and Building Materials. 113, 5-27. 
- Anil, Ö., 2006. Improving shear capacity of RC T-beams using CFRP composites

$494 \quad$ subjected to cyclic load. Cement and Concrete Composites, 28(7), pp.638-649.

495 - Anil, Ö., 2008. Strengthening of RC T-section beams with low strength concrete using

496 CFRP composites subjected to cyclic load. Construction and Building Materials, 22(12), 497 pp.2355-2368.

498

- Bousselham, A. and Chaallal, O., 2008. Mechanisms of shear resistance of concrete 499 beams strengthened in shear with externally bonded FRP. Journal of Composites for $500 \quad$ Construction, 12(5), pp.499-512.

501

- CAN/CSA-S6-06, 2006. Canadian Highway Bridge design code. Canadian Standards $502 \quad$ Association. Mississauga, Ontario.

503

- Carolin, A. and Täljsten, B., 2005. Experimental study of strengthening for increased 504 shear bearing capacity. Journal of Composites for Construction, 9(6), pp.488-496.

- Clarke, J.L. ed., 2002. Structural lightweight aggregate concrete. CRC Press.

- D. Kim and W. M. Sebastian "Parametric study of bond failure in concrete beams 507 externally strengthened with fibre reinforced polymer plates" Magazine of Concrete $508 \quad$ Research 2002 54:1, 47-59.

- Eurocode 2 (2014). BS EN 1992-1-1:2004+A1:2014. Eurocode 2: Design of concrete 510 structures-Part 1-1: General rules and rules for buildings. European Committee for 511 Standardizat ion (CEN). Brussels, Belgium.

512 - Foster, R. M., Brindley, M., Lees, J. M., Ibell, T. J., Morley, C. T., Darby, A. P., \& 513 Evernden, M. C. (2016). Experimental Investigation of Reinforced Concrete T-Beams 
$515 \quad$ Construction, 04016086.

- Kani, G.N.J., 1966. Basic facts concerning shear failure. Am Concrete Inst Journal \& $517 \quad$ Proceedings.

- Khalifa, A. and Nanni, A., 2002. Rehabilitation of rectangular simply supported RC beams with shear deficiencies using CFRP composites. Construction and building materials, 16(3), pp.135-146.

- Kim, Yun Gon (2011). Shear behavior of reinforced concrete T-beams strengthened with

522 carbon fiber reinforced polymer (CFRP) sheets and CFRP anchors. (PhD. Thesis, The University of Texas at Austin), 431.

524

- Lee, H.K., Cheong, S.H., Ha, S.K. and Lee, C.G., 2011. Behavior and performance of RC T-section deep beams externally strengthened in shear with CFRP sheets. Composite

526 Structures, 93(2), pp.911-922.

527

- Leung, C.K., Chen, Z., Lee, S., Ng, M., Xu, M. and Tang, J., 2007. Effect of size on the 528 failure of geometrically similar concrete beams strengthened in shear with FRP strips. 529 Journal of Composites for Construction, 11(5), pp.487-496. $531 \quad$ 1, July.

- Martian, B., and Pantazopoulou, S.J. (2001). Effect of bond, aggregate interlock and dowel action on the shear strength degradation of reinforced concrete. Engineering Structures 23, 214-227. 
- Mofidi, A. and Chaallal, O., 2011. Shear strengthening of RC beams with externally bonded FRP composites: Effect of strip-width-to-strip-spacing ratio. Journal of Composites for Construction, 15(5), pp.732-742.

- Monti, G., \& Liotta, M. A. (2007). Tests and design equations for FRP-strengthening in shear. Construction and Building Materials, 21(4), 799-809.

- Pellegrino, C. and Modena, C., 2002. Fiber reinforced polymer shear strengthening of reinforced concrete beams with transverse steel reinforcement. Journal of Composites for Construction, 6(2), pp.104-111.

- Sundarraja, M.C. and Rajamohan, S., 2009. Strengthening of RC beams in shear using GFRP inclined strips-An experimental study. Construction and Building Materials, 23(2), pp.856-864.

- TR-55, 2013, “Design Guidance for Strengthening Concrete Structures Using Fibre Composites Materials,” Concrete Society, CS-TR-55-UK, Technical Report No. 55, third edition., Report of a Concrete Society Committee, Eynsham, UK, 2013.

- Triantafillou, T.C., 1998. Shear strengthening of reinforced concrete beams using epoxybonded FRP composites. ACI structural journal, 95(2).

- Weber UK, 2008. High-performance carbon fibre sheet reinforcement for structural strengthening. Technical Report, July.

- You, Z. G., Wang, X. G., Liu, G. H., Chen, H. B., \& Li, S. X. (2017). Shear behaviour of hybrid fibre-reinforced SCC T-beams. Magazine of Concrete Research, 1-20.

- Zhang, J-P. "Diagonal cracking and shear strength of reinforced concrete beams." Magazine of Concrete Research 49, no. 178 (1997): 55-65. 
557 